\title{
Development of a geographical exploration technique for detecting obstacles of trenchless engineering
}

\author{
Guo Yun Feng ${ }^{1, a}$ \\ ${ }^{1}$ Fujian Key Laboratory of Geohazard Prevention, Fuzhou 350002, China. \\ a164856657@qq.com
}

\begin{abstract}
Keywords: obstacles detection, cross-hole seismic tomography, horizontal directional drilling (HDD), trenchless engineering
\end{abstract}

\begin{abstract}
This paper develops a geographical exploration technique for detecting obstacles of trenchless engineering by integrating cross-hole seismic tomography and horizontal directional drilling (HDD) technique. Firstly, several small-diameter holes along underground engineering are drilled, and Polyethylene (PE) pipes are installed on the designed path. Then, detecting instrumentations are placed in PE pipes to obtain soil conditions and to identify the obstacles of exploration zone with the aid of the cross-hole seismic tomography. A water main pipe constructed by Pipejacking technique is taken as an example to verify the feasibility of the proposed method. The field results show that the proposed method has capable of detecting obstacles for trenchless engineering.
\end{abstract}

\section{Introduction}

Trenchless techniques such as Pipejacking and Microtunneling have been steadily growing in the installation and renovation of underground pipelines in urban areas owing to the little disruption to traffic and nearby businesses [1]. It is important to detect the obstacles in the trenchless zone for successful installation. In contrast on open cut methods, the soil data is seen indirectly for trenchless methods, which may bring high risks during construction. Therefore, it is essential to develop a favorable means of detecting the sub-surface conditions at a site.

There are several methods have been used for detecting the sub-surface conditions. Boreholes are the most primitive means for sub-surface investigation, which is able to obtain the direct results at the borehole positions. However, due to the fact that municipal pipeline projects such as gas-, water-, and telecommunications-industries usually are linear underground structures, the limit borehole positions along the route only provide a little information. It will increase the risk of trenchless projects because of the lack of soil data. Several geophysical exploration methods have been used extensively to detect underground information, which originally developed for natural resources exploration [2]. Unlike boreholes, the geophysical exploration methods assess ground conditions by measuring indirectly data (such as velocity, attenuation and wavelength of sound) which is controlled by ground properties. Among these existing geophysical exploration methods, the cross-hole seismic tomography is the most efficient exploration tool for detecting ground conditions. So far, a large number of applications and researches about this method have been reported in the literature. S. Sakai and T. Takatsuka [3] develop a new electric wave exploration system for detecting shallow strata boundaries in urban areas and give three experiments to verify its effectiveness. R.S.Bichkar et al [4] present a genetic algorithm approach for detecting sub-surface voids in cross-hole seismic tomography. L.F. Trivino and B. Mohanty [5] assess the crack initiation and propagation in rock from explosion-induced stress waves and gas expansion by cross-hole seismometry and FEM-DEM method. However, with the investigation and application of it increasing, the problems gradually emerge in the cross-hole seismic method applying in detection of ground conditions, involves:

(1) Cross-hole configuration. Boreholes of cross-hole seismic tomography are usually perpendicular to the ground. Because underground pipelines in urban areas usually are linear 
underground structures, this cross-hole configuration only shows the results at the sections and the limit number along the planned route give insufficient information.

(2) Image resolution and accuracy. The distances of boreholes direct determine the image resolution and accuracy. In the filed surveys, the cross-hole configuration scheme needs to consider the distance of boreholes and the cost.

(3) Complex surface conditions. Municipal pipelines are usually beneath the road and constructed using trenchless methods when roads have existed. Drilling on the ground inevitably affect the traffic. In additional, difficulties exist in the detection of soil conditions beneath existing structures when subway crosses the existing buildings.

In view of the above problems, a geographical exploration technique for detecting obstacles of trenchless engineering (PN: ZL201310305447.5) is proposed [6]. By integrating the HDD technique and cross-hole seismic tomography, the soil conditions and obstacles in trenchless zones are detected. A water main pipe constructed by Pipejacking technique is taken as an example to verify the feasibility of proposed method.

\section{Development of a geographical exploration technique}

\subsection{Horizontal directional drilling (HDD)}

The HDD technique dates back to 1891, when the first patent was granted for equipment to place a horizontal hole from a vertical well [7]. The use of this technology has increased dramatically since the mid-1980s because its environmentally friendly character.

The HDD process consists of three stages: pilot bore, back reaming, and pipe installation [8]. The pilot bore stage consists of drilling a borehole along the designed path by using a small-diameter drill. Once the pilot hole is completed, the dill head is switch to a reamer. During the back reaming stage, the reamer is pulled back to enlarge the borepath. On the final pipe installation stage, the pipe installation can either be performed in conjunction with the reaming stage, or after the reaming is completed.

\subsection{Cross-hole seismic tomography}

The cross-hole seismic tomography involves the measurement of the travel times of ray path between two or more boreholes in order to derive an image of seismic velocity in the intervening ground [9].

The cross-hole seismic tomographic processing consists of measuring the travel times of all rays and restructuring the velocity distribution of target exploration zones. Firstly, the seismic sources and seismic receivers are placed in two boreholes. The travel times of each source-receiver pair are collected. Then, the velocity distributions between the boreholes are reconstructed by the aid of mathematical inversion approaches such as the back-projection technique [10], the algebraic reconstruction technique [11], the genetic algorithm-based technique [4] and so on. Because each soil property is corresponding to a velocity value, the anomalous of the resulting velocity image can be regard as obstacles.

\subsection{Proposed geographical exploration technique}

In this paper, a geographical exploration technique based on HDD technique and cross-hole seismic tomography is developed to identify the obstacles in tunneling zones of trenchless projects, especially for linear underground engineering (as shown in Fig.1).

The detail processing is:

(1) Several horizontal holes along tunneling direction are drilled by the use of HDD technique. The holes are closed to the tunneling zones. The borepath (including start point, end point, and pipes number and so on) is designed according to the ground conditions and exploration accuracy. Three borepath schemes are presented in Fig.2. Small-diameter PE pipe (usually 150mm) is placed in holes due to its flexibility, abrasion resistance, and toughness. 


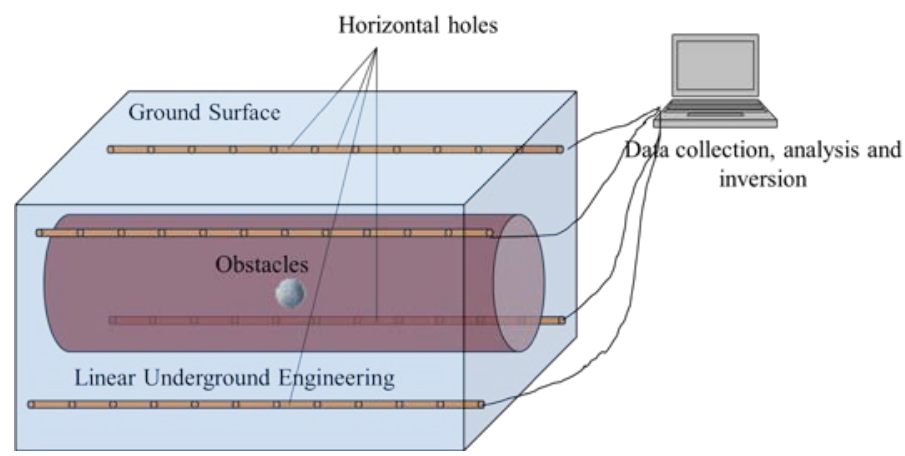

Fig.1 Geographical exploration technique for detecting obstacles of trenchless engineering

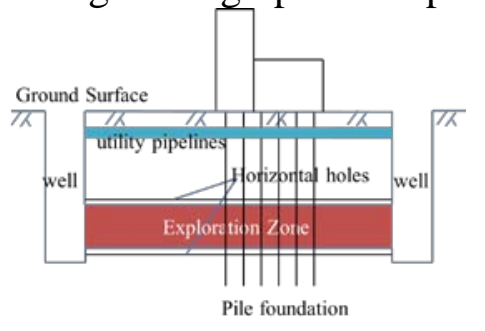

(a) Scheme 1

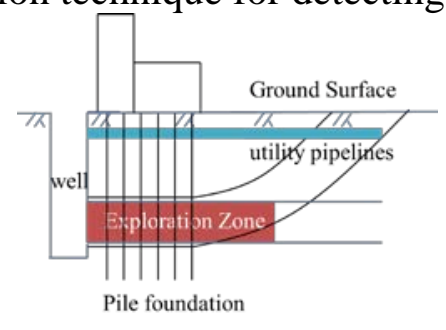

(b) Scheme 2

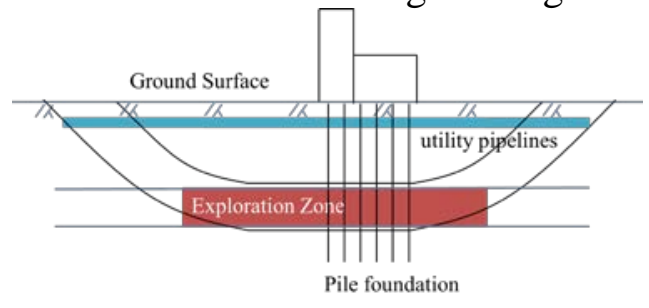

(c) Scheme 3

Fig.2 Design path schemes

(2) The geometry positions of boreholes are measured by the use of gyroscope to minimize the error of the following velocity image.

(3) Sources and receives are placed in boreholes. The boreholes layouts are depend on tunneling area and exploration. Fig.3 shows three boreholes layouts.

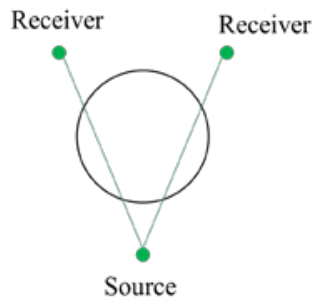

(a) Scheme 1

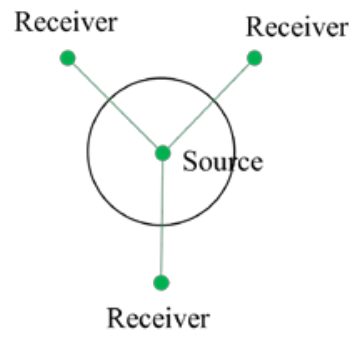

(b) Scheme 2

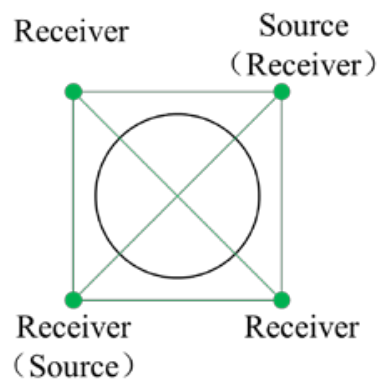

(c) Scheme 3

Fig.3 Schematic diagrams of drill layouts

(4) The velocity image is termed a tomogram by using measurements taken using a large number of rays with wide angular ray coverage (as illustrate in Fig.4). Then, the anomalous velocity zones are identified.

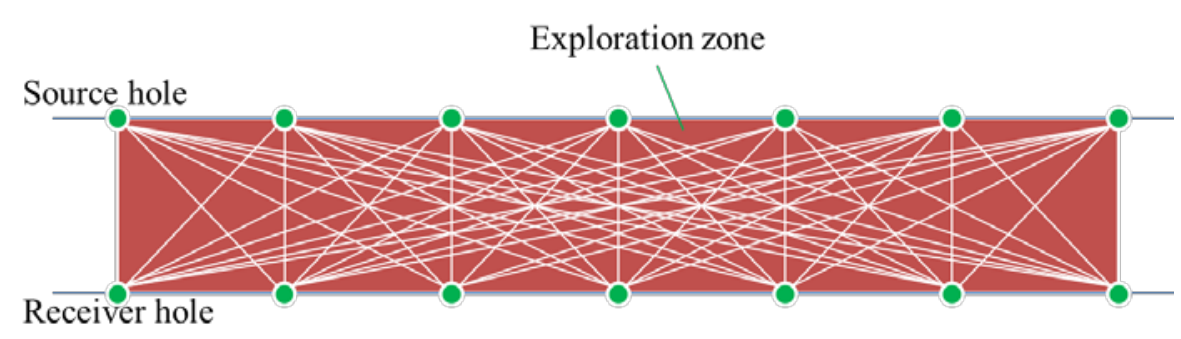

Fig.4 Cross-hole configuration

\section{Case studies}

The proposed technique is applied to explore the tunneling zone of a water main pipe beneath existing bridge. The pipe is constructed by Pipejacking technique. The diameter and depth of water pipe are $1000 \mathrm{~mm}$ and $10.5 \mathrm{~m}$. The bridge width is about $30 \mathrm{~m}$. The obstacles such as the piers of bridge, ripraps 
and root may appear in the tunneling zones. Therefore, it is necessary to explore the obstacles distributions for successfully construction of the water pipe.

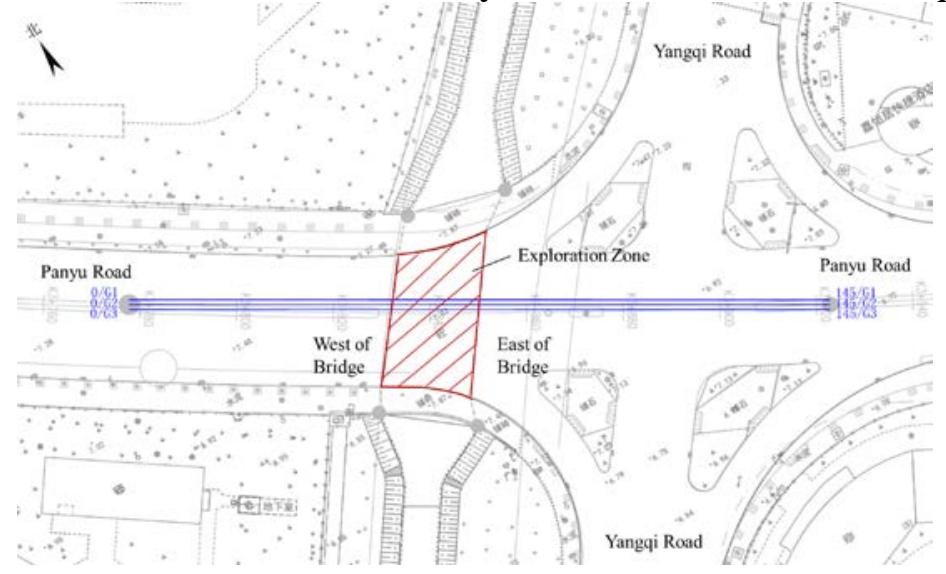

Fig.5 Exploration zone

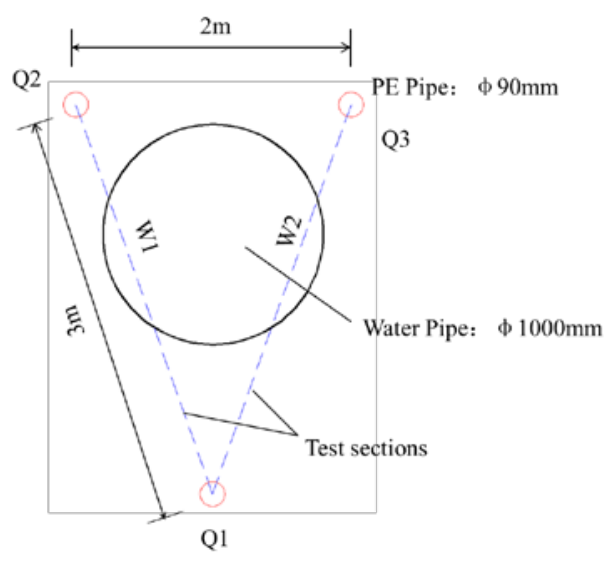

Fig.6 Source-receiver geometry and test sections

\subsection{Exploration scheme}

The test zone is taken the width of bridge plus $14 \mathrm{~m}$ on the both sides. The boreholes paths constructed by the HDD technique are design as Fig. 2 (b). The enter angle and exit angle of PE pipe are $20^{\circ}$. The maximum pull back force and torque of device for horizontal drilling are $380 \mathrm{kN}$ and $12 \mathrm{kN} \cdot \mathrm{m}$. A total of three PE pipes defined as Q1, Q2, and Q3 are placed. The diameter of pipes is $90 \mathrm{~mm}$. the sparker source is placed in Q1, while the hydrophone receivers are placed in Q2 and Q3. The distance between source and receiver are 3m. A total of two sections defined as W1 and W2 is tested. The cross-hole configuration is show in Fig.6.

\subsection{Results and discussions}

Fig.7 and Fig.8 show the resulting image of W1 and W2. It is seen that the average velocity of test zones is $1800 \mathrm{~m} / \mathrm{s}$, and some anomalous zones (as listed in Table 1) are appeared in the exploration zone. These anomalous zones are beneath the bridges, which may be stones. The following boreholes verify these results. It is shows that the proposed method is able to detect the soil conditions and identify the obstacles.

Table 1 anomalous zones

\begin{tabular}{cccc}
\hline Section & Number & Stake & Depth \\
\hline \multirow{5}{*}{ W1 } & 1 & $40.5 \sim 44$ & $-10.5 \sim-11.5$ \\
& 2 & $59.5 \sim 61$ & $-10 \sim-11.5$ \\
& 3 & $78.5 \sim 81.5$ & $-9 \sim-9.5$ \\
& 4 & $86.5 \sim 89$ & $-10 \sim-11$ \\
\hline \multirow{4}{*}{ W2 } & 1 & $42.5 \sim 46$ & $-8.5 \sim-9$ \\
& 2 & $61 \sim 64$ & $-10 \sim-11$ \\
& 3 & $71 \sim 78$ & $-9 \sim-10.5$ \\
& 4 & $86 \sim 91$ & $-8.5 \sim-10$ \\
\hline
\end{tabular}

\section{Conclusions}

A new geophysical exploration technique based on HDD technique and cross-hole seismic tomography is developed to detect the obstacles in the tunneling zones of trenchless projects. A water pipe project constructed by Pipejacking technique is taken as an example to verify the feasibility of proposed method. The test results shown that the proposed method has capable of identifying the anomalous zones and little impact on ground. So far, this method has applied to several projects and produces a good effect. Authors believe that this method would able to expand on other similar engineering, such as subway, electric power tunnel, utility tunneling and so on. 


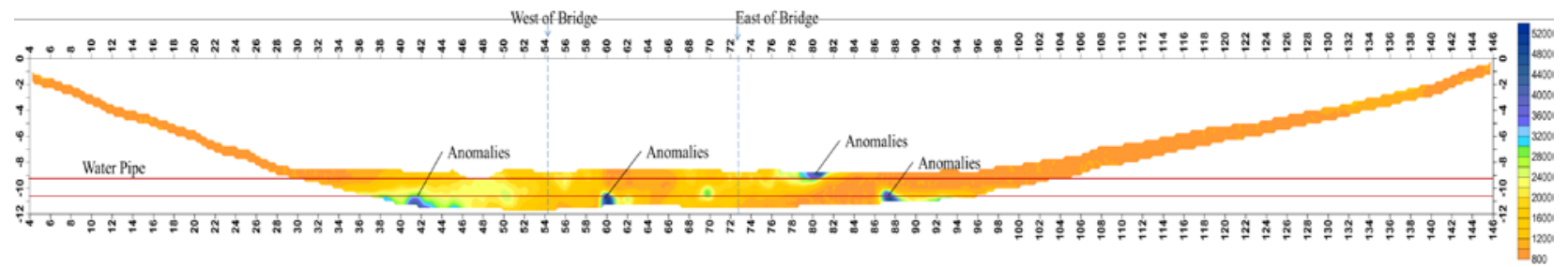

Fig.7 Imaging results of W1

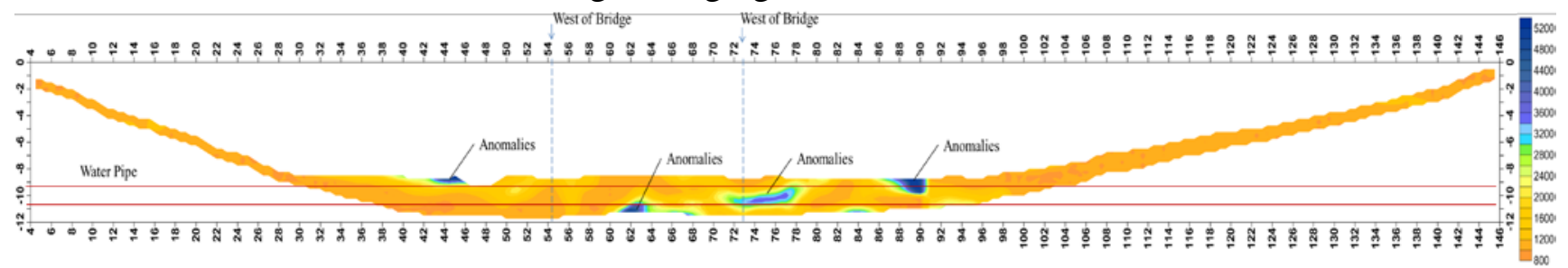

Fig.8 Imaging results of W2

\section{References}

[1] J.J. Struzziery, A.A. Spruch, C.A. Blondin, Trenchless pipe repair for urban renewal project, Journal of New England Water Environment Association. 32(1998)118-125.

[2] D. Bruhn, G. Potsdam, Geophysical exploration methods at European sites. Section 5.2 Geothermics, Germany, 2006.

[3] S. Sakai and T. Takatsuka, Development of a geophysical exploration technique for detecting shallow strata boundaries, Tunn. Undergr. Sp. Tech. 14(1999) 21-29.

[4] R.S. Bichkar, S.K. Singh and A.K.Ray, Genetic algorithmic approach to the detection of subsurface voids in cross-hole seismic tomography, Pattern Recogn. Lett. 19(1998) 527-536.

[5] L.F. Trivino and B. Mohanty, Assessment of crack initiation and propagation in rock from explosion-induced stress waves and gas expansion by cross-hole seismometry and FEM-DEM method, Int. J. Rock. Mech. Min. 77(2015)287-299.

[6] C. Xia, X.L. Gao, Y, Chen, China Patent 201,310,305,447(2013).

[7] R.Carpenter, Embattled HDD industry sees change as necessary, ultimately beneficial. Undergr. Constr, 57(2002)30-32.

[8] S. Gokhale, R. Hamm, R. Sterling, A comprehensive survey on the state of horizontal directional drilling in the North America provides an inside look at this increasingly growing industry, Directional Drilling, 7(1999)20-23.

[9]P.D. Jackson, D.A. Gunn, R.C. Flint, et al. Cross-hole seismic measurements for detection of disturbed ground beneath existing structures, Ndt \& E Int, 34(2001)55-162.

[10] P. Gilbert, Iterative methods for the reconstruction of three dimensional objects from projections, J. Theor. Biol. 36(1972)105-117.

[11]R.Gordon, A tutorial on ART (Algebraic Reconstruction Techniques). IEEE Trans. Nucl. Sci. 21(1974)78-93. 